\title{
Lumbrical-interosseous recording technique versus routine electrodiagnostic methods in the diagnosis of carpal tunnel syndrome
}

\author{
Figen Yllmaz, ${ }^{1}$ Osman Hakan Gündüz, ${ }^{2}$ Gülseren Akyüz ${ }^{2}$ \\ ${ }^{1}$ Department of Physical Medicine and Rehabilitation, Şişli Hamidiye Etfal Training and Research Hospital, Istanbul, Turkey \\ ${ }^{2}$ Department of Physical Medicine and Rehabilitation, Medical Faculty of Marmara University, Istanbul, Turkey \\ Received: March 2016 Accepted: July 2016
}

\begin{abstract}
Objectives: We aimed to evaluate the sensitivity of second lumbrical-interosseous (L-I) technique and to compare the results with other electrophysiological methods in patients with carpal tunnel syndrome (CTS).

Patients and methods: This cross-sectional study was conducted in an electrophysiology laboratory of a university hospital between January 2003 and January 2004. A total of 102 patients with CTS (174 hands) and 40 healthy controls ( 80 hands) were included. Median motor nerve conduction studies were obtained with recordings from the abductor pollicis brevis (APB), median sensory nerve conduction studies from digits I-III and at palm-wrist segment (P-W), median-ulnar sensory comparison at digit IV (M-U), and median-radial sensory comparison at digit I (M-R) were along with L-I technique.

Results: The highest sensitivities were found in the median sensory conduction velocity across the palm-wrist (88\%), and digit I-wrist segments (80\%), median motor distal latency over the APB (77\%), and L-I study (76\%). The specificities of conventional tests were higher than the sensitivity of L-I method (63\%).

Conclusion: L-I method has a good diagnostic sensitivity in CTS; however, P-W, median sensory nerve conduction velocity at digit I and median distal motor latency are more sensitive than L-I method. Therefore, L-I method can be applied as a supportive technique in the evaluation of patients with CTS.
\end{abstract}

Keywords: Carpal tunnel syndrome; electrophysiology; median neuropathy; nerve conduction study.

Carpal tunnel syndrome (CTS), compression of median nerve in the carpal tunnel at the wrist, is the most common entrapment neuropathy. Earliest symptoms are usually sensory and include pain and paresthesia worsening, particularly at night over the first three digits. ${ }^{[1-3]}$ Hand numbness aggravates during repetitive wrist flexion. Thumb abduction and opposition weakness may be present, and atrophy can be seen as a result of involvement of motor branches.

Although CTS can be suspected with symptoms and clinical findings, electrophysiological confirmation is necessary for the definite diagnosis. ${ }^{[4]}$ Clinical and electrophysiological evaluation can yield a diagnosis of CTS with about $90 \%$ accuracy. ${ }^{[5]}$

A variety of electrophysiological methods are used for the diagnosis of CTS. The routine work-up is the median nerve motor conduction study with recording from the abductor pollicis brevis (APB) muscle, and median nerve sensory conduction study from the digits II or III to wrist and from palm to wrist segments. Besides, comparison of median and ulnar sensory latencies from digit IV, and of median and radial nerve from digit I can be done. ${ }^{[2,6]}$

In addition, there is a technique with recording from the second lumbrical and interosseous muscles with stimulation of median and ulnar nerves, respectively. Yates et al. ${ }^{[7]}$ suggest that as motor fibers of median nerve to thenar muscles course more superficially and anteriorly than lumbrical motor fibers inside the carpal tunnel, they are more likely to be affected from the compression under the flexor retinaculum. Therefore, particularly in severe cases with CTS,

Corresponding author: Figen Yılmaz, MD. Şişli Hamidiye Etfal Eğitim ve Araştırma Hastanesi Fiziksel Tıp ve Rehabilitasyon Kliniği, 34371 Şişli, İstanbul, Turkey. e-mail: figenyilmaz@yahoo.com 
motor axons innervating lumbrical muscles tend to be less traumatized. Since lumbrical responses remain intact in cases with severe CTS refractory to classical median motor and sensory stimulation, measurements of lumbrical-interosseous (L-I) latency difference may be helpful for establishing the diagnosis. ${ }^{[1]}$ Additionally, this technique is relatively rapid and may decrease the number of nerve conduction tests for the diagnosis of CTS. $^{[8]}$

In the literature, L-I motor nerve conduction studies (NCS) performed with median-ulnar nerve stimulation were often compared with median sensory or median motor studies. In these studies, the patients were mostly severe CTS. In this study, we aimed to investigated this technique using both median sensory and motor studies in mostly mild or moderate CTS patients.

\section{PATIENTS AND METHODS}

This study included the patients with the diagnosis of CTS and healthy individuals as the control group between January 2003 and January 2004. Among those referred to our laboratory, 102 patients with CTS (174 hands), having at least one of the clinical signs and who met one or more electrodiagnostic criteria mentioned below were included.

Clinical diagnostic criteria for CTS were as follows: (i) Pain or paresthesia over the region innervated by the median nerve, (ii) pain or paresthesia aggravated at night, (iii) loss of strength in thenar muscles, (iv) thenar muscle atrophy, (v) positive Tinel's sign, and (vi) positive Phalen's sign.

Diagnostic electrophysiological criteria for CTS were as follows: (i) abnormal median sensory nerve conduction from digit II or III to wrist, (ii) abnormal median sensory nerve conduction from palm to wrist, and (iii) prolonged median motor nerve distal latency. ${ }^{[2]}$

The control group consisted of 40 healthy volunteers (80 hands). Patients with diabetes mellitus, rheumatoid arthritis, tuberculosis, hypothyroidism, wrist trauma, polyneuropathy, and those with clinical findings suggestive of CTS were excluded from the control group.

All patients and control subjects were informed about the study and a written informed consent was obtained from each participant. The Medical Faculty of Marmara University Ethics Committe approved the study. The study was conducted in accordance with the principles of the Declaration of Helsinki.

\section{Electrophysiological methods}

The evaluation parameters in this study were as follows: temperature at $>31{ }^{\circ} \mathrm{C}$. The instrument used was Medelec Sapphire 4 ME (Medelec Ltd., Surrey, UK).

For motor conduction studies, a bipolar percutaneous stimulator was used. Superficial recording electrodes were placed over APB (at $8 \mathrm{~cm}$ distance from the stimulus site), second lumbrical muscle (at $10 \mathrm{~cm}$ distance from stimulus site), and second interosseous muscle (at $10 \mathrm{~cm}$ distance from stimulus site). A ground electrode was placed between the recording and the stimulating electrodes in all electrophysiological tests.

Filter settings were as follows: $3 \mathrm{~Hz}-5 \mathrm{kHz}$ for motor NCS and F responses; $20 \mathrm{~Hz}-2 \mathrm{kHz}$ for sensory NCS. Sweep durations were $50 \mathrm{~ms}$ motor NCS and F responses and $20 \mathrm{~ms}$ for sensory NCS. The sensitivity was $1 \mathrm{mV}$ for motor and $20 \mu \mathrm{V}$ for sensory NCS; and $200 \mu \mathrm{V}$ for F responses. Supramaximal stimulation was used in motor NCS.

Motor and sensory latencies were accepted as the onset latencies. The amplitude of compound muscle action potential (CMAP) was measured between the negative and positive peaks, and the amplitude of sensory nerve action potential (SNAP) was calculated as the distance from the isoelectric line to negative peak.

\section{Statistical analysis}

Statistical analysis was performed using the NCSS 2007 program for Windows (NCSS Statistical System for Windows, Kaysville, UT, USA). Descriptive statistics were expressed in frequency, percentage, mean, and standard deviation (SD). A paired t-test was used to compare two extremities in both groups. Two independent samples t-test was used to compare CTS and control groups, while the chi-square test and Fisher's exact test was used to evaluate qualitative data. Distribution of variables was assessed using the Shapiro-Wilks test. A $p$ value of $<0.05$ was considered statistically significant with $95 \%$ confidence interval.

To calculate the sensitivity, specificity, positive predictive value (PPV), negative predictive value (NPV), accuracy, and positive likelihood ratio (LR+), a conventional receiver operating characteristic curve was generated and the area under the curve (AUC) was calculated. 


\section{RESULTS}

Of the study group, five patients were males and 97 patients were females with a mean age of $49.9 \pm 10.1$ (range: 25 to 65) years. Of the control subjects, five were males and 35 were females with a mean age of $48.0 \pm 14.8$ (range: 25 to 65 ) years. There was no significant difference between the two groups $(\mathrm{p}>0.05)$ $\mathrm{p}=0.144$. Bilateral CTS was detected in $74(72.5 \%)$, right CTS in 22 (21.5\%), and left CTS in six patients (5.9\%). Carpal tunnel syndrome was in the dominant hand in 24 patients (23.5\%). According to the American Association of Neuromuscular and Electrodiagnostic Medicine (AANEM) classification, ${ }^{[9]}$ mild (37 hands in $21.2 \%$ ), moderate (96 hands in $55.2 \%$ ), and severe (41 hands in 23.6\%) CTS were found in the study group.

In the CTS group, $92.5 \%$ patients had numbness at the affected region, $72.7 \%$ had a positive Tinel's sign, $55.7 \%$ had a positive Phalen's sign, $8 \%$ had thenar atrophy, $2.3 \%$ had loss of contralateral muscle strength, and $13.2 \%$ had APB weakness. All measurements \pm 2 standard deviation (SD) above or below the control values were considered abnormal, and diagnostic criteria for CTS were established accordingly. These values are summarized in Table 1.

According to the values obtained from CTS patients and control subjects, there were significant

Table 1. Normal and upper/lower limit values obtained from the control group and comparison with the carpal tunnel syndrome group

\begin{tabular}{|c|c|c|c|c|c|}
\hline \multirow[t]{2}{*}{ Nerve, study (recording) } & \multirow[b]{2}{*}{ Parameter } & \multicolumn{2}{|c|}{ Control group } & \multirow{2}{*}{$\frac{\text { CTS group }}{\text { Mean } \pm \text { SD }}$} & \multirow[b]{2}{*}{$p$} \\
\hline & & Mean \pm SD & Upper/lower limit* & & \\
\hline Median motor APB & $\begin{array}{l}\text { Distal latency (ms) } \\
\text { CMAP amplitude (mV) } \\
\text { CV (m/s) } \\
\text { Min F latency (ms) }\end{array}$ & $\begin{array}{r}3.1 \pm 0.4 \\
10.1 \pm 3.0 \\
59.7 \pm 4.5 \\
25.0 \pm 1.4\end{array}$ & $\begin{array}{l}>3.78 \\
<4.05 \\
<50.73 \\
>27.81\end{array}$ & $\begin{array}{r}4.5 \pm 1.1 \\
9.3 \pm 6.2 \\
56.3 \pm 7.2 \\
27.7 \pm 2.9\end{array}$ & $\begin{array}{c}0.0001 \dagger \\
0.426 \\
0.0001 \dagger \\
0.0001 \dagger\end{array}$ \\
\hline Median motor ( $2^{\text {nd }}$ lumbrical) & $\begin{array}{l}\text { Latency (ms) } \\
\text { CMAP amplitude (mV) }\end{array}$ & $\begin{array}{l}3.2 \pm 0.3 \\
3.2 \pm 1.2\end{array}$ & $\begin{array}{l}>3.86 \\
<0.75\end{array}$ & $\begin{array}{l}4.6 \pm 1.4 \\
2.2 \pm 1.4\end{array}$ & $\begin{array}{l}0.0001 \dagger \\
0.0001 \dagger\end{array}$ \\
\hline Ulnar motor ( $2^{\text {nd }}$ interosseus) & $\begin{array}{l}\text { Latency (ms) } \\
\text { CMAP amplitude (mV) }\end{array}$ & $\begin{array}{l}3.1 \pm 0.3 \\
8.3 \pm 1.9\end{array}$ & $\begin{array}{l}>3.62 \\
<4.57\end{array}$ & $\begin{array}{l}3.2 \pm 0.3 \\
7.7 \pm 1.9\end{array}$ & $\begin{array}{l}0.001 \dagger \\
0.016 \dagger\end{array}$ \\
\hline Median-ulnar (lumbrical-interossei) & $\begin{array}{l}\text { Lumbrical-interossei motor } \\
\text { latency difference (L-I) (Ms) }\end{array}$ & $0.1 \pm 0.2$ & $>0.60$ & $1.4 \pm 1.3$ & $0.0001 \dagger$ \\
\hline Ulnar motor (ADM) & $\begin{array}{l}\text { Distal latency (ms) } \\
\text { CMAP amplitude (mV) } \\
\text { CV (m/s) (forearm) } \\
\text { Min F latency (ms) }\end{array}$ & $\begin{array}{r}2.4 \pm 0.3 \\
9.1 \pm 2.3 \\
67.5 \pm 5.0 \\
24.5 \pm 1.3\end{array}$ & $\begin{array}{l}>2.86 \\
<4.57 \\
<57.42 \\
>27.17\end{array}$ & $\begin{array}{r}2.4 \pm 0.3 \\
8.5 \pm 2.5 \\
65.0 \pm 5.5 \\
24.8 \pm 1.8\end{array}$ & $\begin{array}{c}0.142 \\
0.043 \dagger \\
0.004 \dagger \\
0.140\end{array}$ \\
\hline Median sensory (digit IV) $(13 \mathrm{~cm})$ & $\begin{array}{l}\text { Amplitude }(\mu \mathrm{V}) \\
\mathrm{CV}(\mathrm{m} / \mathrm{s})\end{array}$ & $\begin{array}{l}23.3 \pm 8.2 \\
52.0 \pm 7.1\end{array}$ & $\begin{array}{l}<6.98 \\
>37.67\end{array}$ & $\begin{array}{l}18.0 \pm 9.1 \\
46.6 \pm 10.5\end{array}$ & $\begin{array}{l}0.0001 \dagger \\
0.0001 \dagger\end{array}$ \\
\hline Median sensory (digit III) $(13 \mathrm{~cm})$ & $\begin{array}{l}\text { Amplitude }(\mu \mathrm{V}) \\
\mathrm{CV}(\mathrm{m} / \mathrm{s})\end{array}$ & $\begin{array}{l}39.5 \pm 12.8 \\
51.9 \pm 5.9\end{array}$ & $\begin{array}{l}<13.79 \\
>40.09\end{array}$ & $\begin{array}{l}26.2 \pm 13.7 \\
38.8 \pm 7.1\end{array}$ & $\begin{array}{l}0.0001 \dagger \\
0.0001 \dagger\end{array}$ \\
\hline Median sensory (digit II) $(13 \mathrm{~cm})$ & $\begin{array}{l}\text { Amplitude }(\mu \mathrm{V}) \\
\mathrm{CV}(\mathrm{m} / \mathrm{s})\end{array}$ & $\begin{array}{l}38.8 \pm 14.1 \\
52.3 \pm 6.0\end{array}$ & $\begin{array}{l}<10.62 \\
<40.36\end{array}$ & $\begin{array}{l}28.0 \pm 14.3 \\
39.5 \pm 6.7\end{array}$ & $\begin{array}{l}0.0001 \dagger \\
0.0001 \dagger\end{array}$ \\
\hline Median sensory (digit I) $(10 \mathrm{~cm})$ & $\begin{array}{l}\text { Amplitude }(\mu \mathrm{V}) \\
\mathrm{CV}(\mathrm{m} / \mathrm{s})\end{array}$ & $\begin{array}{l}46.9 \pm 17.1 \\
47.3 \pm 4.9\end{array}$ & $\begin{array}{l}<12.65 \\
<39.95\end{array}$ & $\begin{array}{l}26.6 \pm 16.1 \\
34.1 \pm 6.8\end{array}$ & $\begin{array}{l}0.0001 \dagger \\
0.0001 \dagger\end{array}$ \\
\hline Median sensory (palm-wrist) $(7 \mathrm{~cm})$ & $\begin{array}{l}\text { Amplitude }(\mu \mathrm{V}) \\
\mathrm{CV}(\mathrm{m} / \mathrm{s})\end{array}$ & $\begin{array}{l}34.7 \pm 13.6 \\
46.5 \pm 4.9\end{array}$ & $\begin{array}{l}<7.41 \\
<36.76\end{array}$ & $\begin{array}{l}21.6 \pm 10.3 \\
31.2 \pm 5.8\end{array}$ & $\begin{array}{l}0.0001 \dagger \\
0.0001 \dagger\end{array}$ \\
\hline Radial sensory (digit I) $(10 \mathrm{~cm})$ & $\begin{array}{l}\text { Amplitude }(\mu \mathrm{V}) \\
\mathrm{CV}(\mathrm{m} / \mathrm{s})\end{array}$ & $\begin{array}{l}15.8 \pm 6.0 \\
49.6 \pm 4.8\end{array}$ & $\begin{array}{l}<3.87 \\
<39.95\end{array}$ & $\begin{array}{l}12.4 \pm 5.6 \\
48.4 \pm 6.4\end{array}$ & $\begin{array}{c}0.0001 \dagger \\
0.137\end{array}$ \\
\hline Ulnar sensory (digit IV) $(13 \mathrm{~cm})$ & $\begin{array}{l}\text { Amplitude }(\mu \mathrm{V}) \\
\mathrm{CV}(\mathrm{m} / \mathrm{s})\end{array}$ & $\begin{array}{l}27.1 \pm 10.8 \\
55.5 \pm 5.3\end{array}$ & $\begin{array}{l}<5.54 \\
<45.01\end{array}$ & $\begin{array}{l}26.8 \pm 10.5 \\
54.1 \pm 5.6\end{array}$ & $\begin{array}{c}0.262 \\
0.027 \dagger\end{array}$ \\
\hline Ulnar sensory (digit V) $(11 \mathrm{~cm})$ & $\begin{array}{l}\text { Amplitude }(\mu \mathrm{V}) \\
\mathrm{CV}(\mathrm{m} / \mathrm{s})\end{array}$ & $\begin{array}{l}37.1 \pm 12.3 \\
51.8 \pm 4.9\end{array}$ & $\begin{array}{l}<12.51 \\
<42.04\end{array}$ & $\begin{array}{l}37.9 \pm 11.9 \\
51.3 \pm 4.6\end{array}$ & $\begin{array}{l}0.888 \\
0.133\end{array}$ \\
\hline $\begin{array}{l}\text { Median-ulnar sensory latency } \\
\text { difference at digit IV (M-U) }\end{array}$ & (ms) & $0.2 \pm 0.4$ & $>0.89$ & $0.5 \pm 0.7$ & $0.0001 \dagger$ \\
\hline $\begin{array}{l}\text { Median-radial sensory latency } \\
\text { difference at digit I (M-R) }\end{array}$ & $(\mathrm{ms})$ & $0.1 \pm 0.3$ & $>0.60$ & $1.0 \pm 0.7$ & $0.0001 \dagger$ \\
\hline
\end{tabular}

CTS: Carpal tunnel syndrome; SD: Standard deviation; ${ }^{\star} \pm 2$ SD values; APB: Abductor pollicis brevis; CMAP: Compound muscle action potential; CV: Conduction velocity; ADM: Abductor digiti minimi; $\dagger: \mathrm{p}<0,05$ statistically significant; Two independent samples t-test. 
Table 2. Sensitivities, specificities, positive and negative predictive, accuracy and likelihood ratio values according \pm 2 SD values of electrodiagnostic methods

\begin{tabular}{|c|c|c|c|c|c|c|c|c|}
\hline & Sensitivity & Specificity & PPV & NPV & Accuracy & LR & AUC & $95 \% \mathrm{CI}$ \\
\hline Median motor distal latency APB & 0.77 & 0.99 & 0.99 & 0.64 & 0.83 & 2.70 & 0.957 & $0.912-0.992$ \\
\hline Median digit II-wrist sensory CV & 0.64 & 0.97 & 0.98 & 0.52 & 0.83 & 2.66 & 0.940 & $0.874-0.975$ \\
\hline Median digit III-wrist sensory CV & 0.75 & 0.96 & 0.98 & 0.60 & 0.77 & 2.25 & 0.934 & $0.838-0.955$ \\
\hline Median palm-wrist sensory CV & 0.88 & 0.97 & 0.99 & 0.76 & 0.81 & 2.46 & 0.963 & $0.893-0.986$ \\
\hline \multicolumn{9}{|l|}{ Lumbrical interossei motor latency } \\
\hline difference (L-I) & 0.76 & 0.63 & 0.82 & 0.54 & 0.82 & 1.20 & 0.842 & $0.727-0.894$ \\
\hline Median digit IV latency ulnar digit IV latency & 0.60 & 0.73 & 0.83 & 0.45 & 0.54 & 1.75 & 0.671 & $0.546-0.789$ \\
\hline Median digit I latency-radial digit I latency & 0.76 & 0.55 & 0.79 & 0.51 & 0.79 & 1.23 & 0.926 & $0.896-0.957$ \\
\hline
\end{tabular}

PPV: Positive predictive value; NPV: Negative predictive value; LR: Likelihood ratio; AUC: Area under ROC curve; CI: Confidence interval; APB: Abductor pollicis brevis; CV: Conduction velocity.

differences in the median motor distal latency (MDL), median minimum $\mathrm{F}$ responses, L-I, M-U, $\mathrm{M}-\mathrm{R}$, digit I, II, III and palm-wrist (median nerve) latencies, amplitudes, and conduction velocities $(\mathrm{p}<0.0001)$ (Table 1).

On the other hand, there was no significant difference in the ulnar nerve digit $\mathrm{V}$ sensory latencies, amplitudes, ulnar nerve distal motor latencies, and ulnar nerve minimum $F$ responses between the CTS patients and control group ( $>0.05)$. Although ulnar nerve conduction velocities in the control group across the wrist-posterior cubital region were significantly lower than those of CTS patients, conduction velocities of both groups were within normal limits.

Sensitivities, specificities, PPV, NPV, accuracy, LR+ and AUC values of the aforementioned diagnostic tests for CTS are given in Table 2. The highest sensitivities were found in the median sensory nerve conduction velocity across the palmwrist, and digit I-wrist segments, median motor distal latency over the APB muscle, and L-I study. The highest accuracies were found in the median motor distal latency over the APB muscle, L-I study and median sensory nerve conduction velocity across the palm-wrist. Specificities of the conventional

Table 3. Demographic and clinic results of control and carpal tunnel syndrome groups

\begin{tabular}{|c|c|c|c|c|c|c|c|}
\hline & \multicolumn{3}{|c|}{ Control group } & \multicolumn{3}{|c|}{ CTS group } & \multirow[b]{2}{*}{$p$} \\
\hline & $\mathrm{n}$ & $\%$ & Mean \pm SD & $\mathrm{n}$ & $\%$ & Mean \pm SD & \\
\hline Age (year) & & & $48.0 \pm 14.8$ & & & $49.9 \pm 10.1$ & \\
\hline Sex & & & & & & & 0.144 \\
\hline Male & 5 & & & 5 & & & \\
\hline Female & 35 & & & 97 & & & \\
\hline \multicolumn{8}{|l|}{ Numbness } \\
\hline$(-)$ & 80 & 100 & & 13 & 7.5 & & 0.0001 \\
\hline$(+)$ & 0 & 0 & & 161 & 92.5 & & \\
\hline \multicolumn{8}{|l|}{ Tinnel + } \\
\hline$(-)$ & 80 & 100 & & 48 & 27.6 & & 0.0001 \\
\hline$(+)$ & 0 & 0 & & 126 & 72.4 & & \\
\hline \multicolumn{8}{|l|}{ Phalen +} \\
\hline$(-)$ & 80 & 100 & & 78 & 44.8 & & 0.0001 \\
\hline$(+)$ & 0 & 0 & & 96 & 55.2 & & \\
\hline \multicolumn{8}{|l|}{ Atrophy + } \\
\hline$(-)$ & 80 & 00 & & 160 & 92 & & 0.006 \\
\hline$(+)$ & 0 & 0 & & 14 & 8 & & \\
\hline \multicolumn{8}{|c|}{ Strength of oppozition +} \\
\hline 4 & 0 & 0 & & 4 & 2.3 & & 0.311 \\
\hline 5 & 80 & 100 & & 170 & 97.7 & & \\
\hline \multicolumn{8}{|c|}{ Strength of abductor pollicis brevis +} \\
\hline 2 & 0 & 0 & & 3 & 1.7 & & \\
\hline 3 & 0 & 0 & & 4 & 2.3 & & \\
\hline 4 & 0 & 0 & & 16 & 9.2 & & $\chi^{2}: 10.21$ \\
\hline 5 & 80 & 100 & & 151 & 86.8 & & $<0.05$ \\
\hline
\end{tabular}

CTS: Carpal tunnel syndrome; SD: Standard deviation; +Fisher's Exact test. 
Table 4. Comparison of right-left hand for all of the patient and control subjects

\begin{tabular}{|c|c|c|c|c|}
\hline & Left & Right & & \\
\hline & Mean \pm SD & Mean \pm SD & $\mathrm{t}$ & $p$ \\
\hline \multicolumn{5}{|l|}{ Median motor APB } \\
\hline Distal latency (ms) & $3.0 \pm 0.4$ & $3.0 \pm 0.3$ & 0.16 & 0.853 \\
\hline CMAP amplitude (mV) & $9.3 \pm 2.5$ & $10.5 \pm 3.5$ & -1.46 & 0.145 \\
\hline $\mathrm{CV}(\mathrm{m} / \mathrm{s})$ & $60.4 \pm 5.8$ & $59.4 \pm 3.3$ & 0.98 & 0.332 \\
\hline Min F latency (ms) & $24.8 \pm 1.4$ & $25.0 \pm 1.3$ & -0.76 & 0.457 \\
\hline \multicolumn{5}{|l|}{ Median motor second lumbrical } \\
\hline Latency $(\mathrm{ms})$ & $3.2 \pm 0.3$ & $3.2 \pm 0.4$ & -0.01 & 0.916 \\
\hline CMAP amplitude (mV) & $3.2 \pm 1.4$ & $3.1 \pm 1.1$ & 0.37 & 0.736 \\
\hline \multicolumn{5}{|l|}{ Ulnar motor second interosseous } \\
\hline Latency $(\mathrm{ms})$ & $3.1 \pm 0.3$ & $3.0 \pm 0.3$ & 0.40 & 0.783 \\
\hline CMAP amplitude (mV) & $8.3 \pm 2.1$ & $8.4 \pm 1.9$ & -0.12 & 0.907 \\
\hline \multicolumn{5}{|l|}{ Ulnar motor } \\
\hline Distal latency (ms) & $2.3 \pm 0.3$ & $2.4 \pm 0.3$ & -0.17 & 0.814 \\
\hline CMAP amplitude (mV) & $9.5 \pm 2.3$ & $9.1 \pm 2.5$ & 0.61 & 0.489 \\
\hline $\mathrm{CV}(\mathrm{m} / \mathrm{s})($ forearm) & $67.6 \pm 5.3$ & $66.9 \pm 5.3$ & 0.59 & 0.495 \\
\hline Min F latency (ms) & $24.4 \pm 1.5$ & $24.4 \pm 1.3$ & -0.20 & 0.853 \\
\hline \multicolumn{5}{|l|}{ Median sensory digit 4} \\
\hline Amplitude $(\mu \mathrm{V})$ & $25.1 \pm 7.9$ & $23.7 \pm 7.8$ & 0.69 & 0.548 \\
\hline $\mathrm{CV}(\mathrm{m} / \mathrm{s})$ & $54.1 \pm 7.2$ & $52.4 \pm 5.8$ & 1.05 & 0.313 \\
\hline \multicolumn{5}{|l|}{ Median sensory digit 3} \\
\hline Amplitude $(\mu \mathrm{V})$ & $42.7 \pm 12.4$ & $38.5 \pm 12.6$ & 1.40 & 0.188 \\
\hline $\mathrm{CV}(\mathrm{m} / \mathrm{s})$ & $52.8 \pm 5.0$ & $53.0 \pm 6.0$ & -0.20 & 0.804 \\
\hline \multicolumn{5}{|l|}{ Median sensory digit 2} \\
\hline Amplitude $(\mu \mathrm{V})$ & $42.5 \pm 14.0$ & $38.9 \pm 13.5$ & 1.24 & 0.221 \\
\hline $\mathrm{CV}(\mathrm{m} / \mathrm{s})$ & $53.7 \pm 5.9$ & $52.9 \pm 5.7$ & 0.60 & 0.496 \\
\hline \multicolumn{5}{|l|}{ Median sensory digit 1} \\
\hline Amplitude $(\mu \mathrm{V})$ & $49.2 \pm 16.8$ & $48.9 \pm 16.4$ & 0.08 & 0.941 \\
\hline $\mathrm{CV}(\mathrm{m} / \mathrm{s})$ & $47.9 \pm 4.8$ & $47.9 \pm 4.7$ & 0.00 & 0.998 \\
\hline \multicolumn{5}{|l|}{ Median sens. palm-wrist } \\
\hline Amplitude $(\mu \mathrm{V})$ & $35.1 \pm 13.0$ & $35.4 \pm 13.8$ & -0.11 & 0.907 \\
\hline $\mathrm{CV}(\mathrm{m} / \mathrm{s})$ & $47.3 \pm 5.7$ & $46.4 \pm 4.1$ & 0.88 & 0.421 \\
\hline \multicolumn{5}{|l|}{ Radial sensory digit 1} \\
\hline Amplitude $(\mu \mathrm{V})$ & $17.0 \pm 5.8$ & $15.6 \pm 6.4$ & 1.04 & 0.310 \\
\hline $\mathrm{CV}(\mathrm{m} / \mathrm{s})$ & $50.3 \pm 5.4$ & $49.1 \pm 4.5$ & 0.93 & 0.335 \\
\hline \multicolumn{5}{|l|}{ Ulnar sensory digit 4} \\
\hline Amplitude $(\mu \mathrm{V})$ & $29.5 \pm 9.9$ & $27.6 \pm 10.9$ & 0.71 & 0.489 \\
\hline $\mathrm{CV}(\mathrm{m} / \mathrm{s})$ & $56.2 \pm 6.0$ & $55.5 \pm 4.6$ & 0.51 & 0.635 \\
\hline \multicolumn{5}{|l|}{ Ulnar sensory digit 5} \\
\hline Amplitude $(\mu \mathrm{V})$ & $39.2 \pm 12.3$ & $37.3 \pm 12.1$ & 0.66 & 0.545 \\
\hline $\mathrm{CV}(\mathrm{m} / \mathrm{s})$ & $51.9 \pm 3.8$ & $52.7 \pm 5.7$ & -0.72 & 0.489 \\
\hline \multicolumn{5}{|c|}{ Lumbrical-interossei motor latency } \\
\hline difference (L-I) & $0.1 \pm 0.2$ & $0.1 \pm 0.2$ & -0.50 & 0.635 \\
\hline \multicolumn{5}{|l|}{ Median-ulnar sensory latency } \\
\hline difference at digit $4(\mathrm{M}-\mathrm{U})$ & $0.1 \pm 0.3$ & $0.1 \pm 0.3$ & -0.20 & 0.853 \\
\hline \multicolumn{5}{|l|}{ Median-radial sensory latency } \\
\hline difference at digit $1(M-R)$ & $0.1 \pm 0.3$ & $0.1 \pm 0.2$ & 0.75 & $>0.05$ \\
\hline
\end{tabular}

tests were usually higher than that of L-I technique (63\%).

\section{DISCUSSION}

Carpal tunnel syndrome is the most common entrapment neuropathy referred to electromyography laboratories. It is more prevalent in women. ${ }^{[2,10,11]}$ Several studies have shown different ages for the onset of CTS ranging between 45.2 and 51 years. ${ }^{[1-14]}$ In our study, female patients predominated (95.1\%) with a mean age of $49.9 \pm 10.1$ years. In many studies, CTS has been more commonly reported in women. ${ }^{[15-17]}$

Carpal tunnel syndrome initially affects the dominant hand and, then, involves the contralateral hand. Bilateral involvement was reported in 46.1 to $62 \%$ of the cases. ${ }^{[18,19]}$ In a study conducted by 
Aydin et al. ${ }^{[14]}$ the mean age for bilateral and dominant hand involvements were 64.5 and $23.5 \%$, respectively. In our study, we found a higher ratio of bilateral CTS (72.5\%), and $23.5 \%$ of CTS cases were diagnosed in the dominant side.

Simpson ${ }^{[20]}$ was the first to describe the use of median nerve motor conduction studies as a diagnostic tool in CTS in 1956. Later, Thomas ${ }^{[3]}$ confirmed the Simpson's ${ }^{[20]}$ assumption. Prolongation of median nerve motor distal latencies reportedly varied between 29 and $81 \%$ in the literature. ${ }^{[21]}$ In our control group, the median nerve motor distal latencies above $3.78 \mathrm{~ms}$ were considered abnormal $(>2 \mathrm{SD}$ above the mean value). In our study group, the mean median nerve motor distal latency was $4.53 \mathrm{~ms}$. In another study, the corresponding values were $3.90 \mathrm{~ms}$ and $4.64 \mathrm{~ms}^{[22]}$ In the aforementioned study, the sensitivity and specificity of measurements of the median nerve motor distal latencies were $78.2 \%$ and $>99 \%$, respectively. We found similar values (75 and 99\%, respectively) in our study. Preston and Logigian ${ }^{[23]}$ also reported 54\% sensitivity of measurements of the median nerve motor distal latency. In their study, Aydin et al. ${ }^{[14]}$ found prolongation of median nerve motor distal latency in approximately $48.6 \%$ of their cases, and the mean median nerve motor distal latency was $4.28 \mathrm{~ms}$.

The comparative evaluation of the recordings from the second lumbrical muscles for median distal motor latencies and ulnar distal motor latencies obtained from the interosseous muscles is another technique assessing the sensitivity of motor NCS. ${ }^{[23,24]}$ It has been shown that motor fibers innervating the thenar muscles are relatively protected, compared to motor branches of the lumbrical muscles. ${ }^{[7]}$ In this technique, nerves are stimulated within the same distance used in classical methods. They are obtained from both muscles using a recording electrode placed immediately lateral to the mid-point of third metacarpal head. ${ }^{[23]} \mathrm{A}$ difference of $>0.4 \mathrm{~ms}$ between the median and ulnar latencies recorded from the second lumbrical and interosseous muscles is considered significant. ${ }^{[9]}$

In our control group, L-I difference values above $0.60 \mathrm{~ms}$ were accepted abnormal. In our study, the cut-off value for the L-I latency difference was $>0.5 \mathrm{~ms}$. In our CTS group, the mean difference was found to be $1.40 \mathrm{~ms}$, whereas it was $0.12 \mathrm{~ms}$ in the control group, indicating a significant difference between the two groups $(\mathrm{p}<0.001)$ (Table 1$)$.

Boonyapisit et al. ${ }^{[10]}$ reported $6.0 \mathrm{~ms}$ for mean L-I value in their severe CTS group, and found the sensitivity of L-I method as $92.8 \%$. In addition, Kodama et al. ${ }^{[25]}$ found the sensitivity of L-I method to be $92 \%$. In our study, we found the sensitivity and specificity of this method to be $76 \%$ and $63 \%$, respectively. Preston and Logigan ${ }^{[23]}$ reported the sensitivity of L-I technique as $95 \%$. In another study in patients with mild CTS, Preston et al. ${ }^{[24]}$ reported $88 \%$ sensitivity for this method.

Furthermore, Ozben et al. ${ }^{[26]}$ found the sensitivity to be $89.4 \%$ and specificity to be $84.4 \%$ with a cut-off value of $\geq 0.5$ in their study. However, based on a cutoff value of $>0.5$ for L-I latency difference, sensitivity and specificity were $86.9 \%$ and $91.3 \%$, respectively. The authors, finally, concluded that this technique could be used as a quick and simple technique in very severe CTS cases, providing extra information.

On the other hand, Argyriou et al. ${ }^{[27]}$ reported the second L-I comparison method to be very sensitive to diagnose CTS in mild CTS cases. Banach et al. ${ }^{[28]}$ also found that there was a strong correlation between the diagnosis of CTS and L-I test, compared to other standardized tests.

Generally accepted consensus for the electrodiagnosis of CTS is that median nerve sensory conduction studies are more sensitive than motor conduction methods. ${ }^{[12,21]}$ In 63 to $97.8 \%$ of patients with CTS, abnormal sensory nerve conduction results across the digit-wrist segment have been issued. ${ }^{[2]}$ The most frequently seen abnormality in the digit-wrist segment is the absence of compound nerve action potentials (CNAPs). Delayed sensory nerve conduction velocity or prolonged sensory latencies rank second in incidence. $^{[2]}$

In a study performed in 55 hands, Macdonell et al. ${ }^{[29]}$ reported that the most prominent slowing in median nerve sensory conduction velocity examinations in CTS was seen in digit I, while minimal delay was noted during digit II recordings. In another study conducted in 375 symptomatic hands, the recordings for sensory nerve conduction velocities were abnormal for all hands in $92 \%$ of digit III, $80 \%$ of digit II, and $64 \%$ of digit I, respectively. ${ }^{[30]}$ In an antidromic sensory conduction study performed in 59 patients with mild CTS demonstrated that recordings for digit I were the most sensitive measurements in the detection of decelerations in focal sensory nerve conduction velocities across wrists. ${ }^{[31]}$

In addition, Aydin et al. ${ }^{[14]}$ found a significant slowing in conduction velocities during the median sensory NCS across digit I (95.4\%), digit III (88\%), and digit II in decreasing order of frequency. 
In our study, sensory nerve conduction velocities across the wrist-digit I, II or III had $80 \%, 64 \%$, and $75 \%$ diagnostic sensitivities. Accordingly, the most sensitive segment for the detection of nerve conduction velocities was digit I-wrist, while the least sensitive one was digit II-wrist segments. Relative protection of the digit II-wrist segment from trauma might be related to the anatomical configuration of median nerve inside the carpal tunnel. Median nerve was also demonstrated most vulnerable to compressive forces at the distal segment of carpal tunnel, where the median nerve divides into motor and sensory branches. At this level, fibers of median nerve passing below transverse carpal ligament and extending to digits I and III run on the anterolateral aspect of the nerve, while those approaching to medial aspect of digit IV parallel the nerve anteromedially. Nerve fibers coursing toward digit II run posteriorly within the confines of central portion of the tunnel. Therefore, it has been suggested that, in CTS, direct compressive or ischemic impact on nerve is not uniformly distributed, and some fibers are more severely affected. ${ }^{[7]}$

Furthermore, palm-wrist sensory nerve conduction studies have higher additive diagnostic sensitivity for CTS. ${ }^{[6]}$ Kimura $^{[32]}$ diagnosed CTS in $63 \%$ of their patients, and adjunctive application of palmar stimulation revealed another $23 \%$ of cases with CTS.

Many laboratories consider palm-wrist sensory nerve conduction studies as a standard diagnostic test for CTS ${ }^{[6]}$ Aydin et al. ${ }^{[14]}$ found prolonged sensory nerve conduction velocities across the palm-digit segments in $98.5 \%$ of their cases. Demirci and Sonel ${ }^{[33]}$ investigated which test was more sensitive in patients with early stage CTS and found that the most sensitive tests were palm-wrist test and median/radial-digit I differential latencies test. In our study, the sensitivity of palm-wrist conduction velocity was found to be $88 \%$, indicating the highest rate of diagnostic accuracy among all NCS to date.

To increase the diagnostic accuracy in cases with normal conventional test results, various comparative methods have been suggested. ${ }^{[6]}$ Measurements of median and ulnar-palmar mixed latencies and median/ ulnar-digit IV differential latencies are most widely used methods. ${ }^{[33,34]}$ Uncini et al. ${ }^{[35]}$ found sensitivities of measurements of digit IV-wrist median-ulnar differential latencies, median-ulnar palmar mixed latencies, and L-I method to be $77 \%, 56 \%$, and $10 \%$, respectively. In a study conducted by Preston et al., ${ }^{[24]}$ the corresponding rates of sensitivity were $91 \%, 97 \%$, and $88 \%$, respectively.

Among the comparative tests, the record of median-ulnar sensory latency difference of the digit IV commonly used in the diagnosis of CTS. Aygul et al. ${ }^{[36]}$ found the sensitivity of this test to be $77 \%$. In our study, the sensitivity of differential latencies of digit IV-median/ulnar nerves was found to be $60 \%$, which was the lowest rate among all NCS. We believe that our established cut-off value of $>0.89 \mathrm{~ms}$ for abnormal differential latencies derived from the results of the control group might contribute to this low rate of sensitivity. In the literature, however, the cut-off value for this test is often $>0.40 \mathrm{~ms}$. In our cases with CTS, the mean differential $\mathrm{M}-\mathrm{U}$ latency was found to be $0.5 \pm 0.7 \mathrm{~ms}$.

In the comparative NCS with median nerve, radial nerve has been preferred over ulnar nerve due to relatively rare occurrence of entrapment of superficial radial nerve. The differential latency of median-ulnar nerve is $<0.5 \mathrm{~ms}$ with antidromic stimulation. ${ }^{[9,34]}$ Pease et al. ${ }^{[37]}$ found CTS in 333 patients using conventional methods with $78 \%$ sensitivity, while this method yielded $87 \%$ sensitivity.

In our study, for the differences in latencies of median-ulnar NCS, the cut-off value was set at 0.60 ms. The sensitivity of this test was $76 \%$. Leblebici et al. $^{[38]}$ and Pease et al. ${ }^{[37]}$ compared median-ulnar and median-radial nerve latency differences in patients with early stage CTS, and both tests were found to be good alternatives to identify early stage CTS patients. ${ }^{[37,38]}$ Eftekharsadat et al. ${ }^{[39]}$ described radialmedian latency difference study and wrist segment nerve conduction velocity study using two-segment technique as the most valuable techniques in the diagnosis of CTS.

In general, the sensitivities of amplitude studies in CTS are low. Cioni et al. ${ }^{[30]}$ revealed that measurements of median nerve SNAP amplitudes were much more inferior to those of sensory nerve conduction velocity, and it must be abandoned as a diagnostic test for CTS. In our study, compared to the control group, digit I-IV and palm-wrist median nerve SNAP amplitudes were significantly lower in the patients with CTS. However, the mean SNAP amplitudes recorded in CTS were above abnormal values. Therefore, we consider that CTS diagnosis cannot be made firmly based on the recordings of SNAP amplitudes alone, and nerve conduction velocities must be calculated.

On the contrary, we found lower sensitivity and specificity of second L-I latency difference technique. 
The reason for this can be that our study group included $75.6 \%$ mild to moderate CTS patients. We believe that, if we had higher rate of severe CTS cases, our values could have been higher. Therefore, the main limitation of our study is that we were unable to evaluate our CTS cases separately according to the grade of involvement. Thus, the sensitivity and specificity of the testing methods of mild, moderate, and serious CTS cases were unable to be evaluated separately.

In conclusion, L-I method has a good diagnostic sensitivity for CTS. However, the sensitivities of median palm-wrist sensory conduction velocity, median digit I-wrist sensory conduction velocity, and median motor distal latency over the APB muscle were higher in our study. Therefore, in the evaluation of cases with CTS, L-I method can be considered as an adjunctive technique. Further large-scale, comparative studies including subgroup analyses for grading the severity of CTS would yield more accurate results about the diagnostic sensitivity of this technique.

\section{Declaration of conflicting interests}

The authors declared no conflicts of interest with respect to the authorship and/or publication of this article.

\section{Funding}

The authors received no financial support for the research and/or authorship of this article.

\section{REFERENCES}

1. Logigian EL, Busis NA, Berger AR, Bruyninckx F, Khalil N, Shahani BT, et al. Lumbrical sparing in carpal tunnel syndrome: anatomic, physiologic, and diagnostic implications. Neurology 1987;37:1499-505.

2. Oh SJ. Nerve conduction in focal neuropathies. In: Oh SJ, editor. Clinical Electromyography, Nerve Conduction Studies. 3rd ed. Philadelphia: Lippincott Williams \& Wilkins; 2003. p. 601-94.

3. Thomas PK. Motor nerve conduction in the carpal tunnel syndrome. Neurology 1960;10:1045-50.

4. Raudino F. Tethered median nerve stress test in the diagnosis of carpal tunnel syndrome. Electromyogr Clin Neurophysiol 2000;40:57-60.

5. Katz JN, Larson MG, Sabra A, Krarup C, Stirrat CR, Sethi $\mathrm{R}$, et al. The carpal tunnel syndrome: diagnostic utility of the history and physical examination findings. Ann Intern Med 1990;112:321-7.

6. Oh SJ. Nerve conduction techniques. In: Oh SJ, editor. Clinical Electromyography, Nerve Conduction Studies. 3rd ed. Philadelphia: Lippincott Williams \& Wilkins; 2003. p. 37-53.

7. Yates SK, Yaworski R, Brown WF. Relative preservation of lumbrical versus thenar motor fibres in neurogenic disorders. J Neurol Neurosurg Psychiatry 1981;44:768-74.

8. Therimadasamy AK, Li E, Wilder-Smith EP. Can studies of the second lumbrical interossei and its premotor potential reduce the number of tests for carpal tunnel syndrome? Muscle Nerve 2007;36:491-6.

9. Stevens JC. AAEM minimonograph \#26: the electrodiagnosis of carpal tunnel syndrome. American Association of Electrodiagnostic Medicine. Muscle Nerve 1997;20:1477-86.

10. Boonyapisit K, Katirji B, Shapiro BE, Preston DC. Lumbrical and interossei recording in severe carpal tunnel syndrome. Muscle Nerve 2002;25:102-5.

11. Chang MH, Wei SJ, Chiang HL, Wang HM, Hsieh PF, Huang SY. Comparison of motor conduction techniques in the diagnosis of carpal tunnel syndrome. Neurology 2002;58:1603-7.

12. Kuntzer T. Carpal tunnel syndrome in 100 patients: sensitivity, specificity of multi-neurophysiological procedures and estimation of axonal loss of motor, sensory and sympathetic median nerve fibers. J Neurol Sci 1994;127:221-9.

13. Padua L, Lo Monaco M, Valente EM, Tonali PA. A useful electrophysiologic parameter for diagnosis of carpal tunnel syndrome. Muscle Nerve 1996;19:48-53.

14. Aydin G, Keleş I, Ozbudak Demir S, Baysal AI. Sensitivity of median sensory nerve conduction tests in digital branches for the diagnosis of carpal tunnel syndrome. Am J Phys Med Rehabil 2004;83:17-21.

15. de Azevedo JW, de Oliveira AB, Nascimento Vd, de Paiva HR Jr, Viecili L, Rocha MA. Profile of patıents on sick leave with carpal tunnel syndrome. Acta Ortop Bras 2015;23:244-6.

16. Violante FS, Farioli A, Graziosi F, Marinelli F, Curti $\mathrm{S}$, Armstrong TJ, et al. Carpal tunnel syndrome and manual work: the OCTOPUS cohort, results of a tenyear longitudinal study. Scand J Work Environ Health 2016;42:280-90.

17. Karne SS, Bhalerao NS. Carpal Tunnel Syndrome in Hypothyroidism. J Clin Diagn Res 2016;10:36-8.

18. Kimura I, Ayyar DR. The carpal tunnel syndrome: electrophysiological aspects of 639 symptomatic extremities. Electromyogr Clin Neurophysiol 1985;25:151-64.

19. Kaul MP, Pagel KJ. Value of the lumbrical-interosseous technique in carpal tunnel syndrome. Am J Phys Med Rehabil 2002;81:691-5.

20. Simpson JA. Electrical signs in the diagnosis of carpal tunnel and related syndromes. J Neurol Neurosurg Psychiatry 1956;19:275-80.

21. Jablecki CK, Andary MT, So YT, Wilkins DE, Williams FH. Literature review of the usefulness of nerve conduction studies and electromyography for the evaluation of patients with carpal tunnel syndrome. AAEM Quality Assurance Committee. Muscle Nerve 1993;16:1392-414.

22. Foresti C, Quadri S, Rasella M, Tironi F, Viscardi M, Ubiali E. Carpal tunnel syndrome: which electrodiagnostic path should we follow? A prospective study of 100 consecutive patients. Electromyogr Clin Neurophysiol 1996;36:377-84.

23. Preston DC, Logigian EL. Lumbrical and interossei recording in carpal tunnel syndrome. Muscle Nerve 1992;15:1253-7.

24. Preston DC, Ross MH, Kothari MJ, Plotkin GM, Venkatesh S, Logigian EL. The median-ulnar latency difference studies are comparable in mild carpal tunnel syndrome. Muscle Nerve 1994;17:1469-71. 
25. Kodama M, Tochikura M, Sasao Y, Kasahara T, Koyama Y, Aono $\mathrm{K}$, et al. What is the most sensitive test for diagnosing carpal tunnel syndrome? Tokai J Exp Clin Med 2014;39:172-7.

26. Ozben S, Acar H, Gunaydin S, Genc F, Ozer F, Ozben H. The second lumbrical-interosseous latency comparison in carpal tunnel syndrome. J Clin Neurophysiol 2012;29:263-7.

27. Argyriou AA, Karanasios P, Makridou A, Makris N. The significance of second lumbrical-interosseous latency comparison in the diagnosis of carpal tunnel syndrome. Acta Neurol Scand 2009;120:198-203.

28. Banach M, Juranek J, Stanisz A. Correlations between the lumbrical-interosseous latency comparison test and standard tests used in the diagnosis of carpal tunnel syndrome. Przegl Lek 2015;72:282-5. [Abstract]

29. Macdonell RA, Schwartz MS, Swash M. Carpal tunnel syndrome: which finger should be tested? An analysis of sensory conduction in digital branches of the median nerve. Muscle Nerve 1990;13:601-6.

30. Cioni R, Passero S, Paradiso C, Giannini F, Battistini N, Rushworth G. Diagnostic specificity of sensory and motor nerve conduction variables in early detection of carpal tunnel syndrome. J Neurol 1989;236:208-13.

31. Kothari MJ, Rutkove SB, Caress JB, Hinchey J, Logigian EL, Preston DC. Comparison of digital sensory studies in patients with carpal tunnel syndrome. Muscle Nerve 1995;18:1272-6.

32. Kimura J. The carpal tunnel syndrome: localization of conduction abnormalities within the distal segment of the median nerve. Brain 1979;102:619-35.

33. Demirci S, Sonel B. Comparison of sensory conduction techniques in the diagnosis of mild idiopathic carpal tunnel syndrome: which finger, which test? Rheumatol Int 2004;24:217-20.

34. Johnson EW, Kukla RD, Wongsam PE, Piedmont A. Sensory latencies to the ring finger: normal values and relation to carpal tunnel syndrome. Arch Phys Med Rehabil 1981;62:206-8.

35. Uncini A, Di Muzio A, Awad J, Manente G, Tafuro M, Gambi D. Sensitivity of three median-to-ulnar comparative tests in diagnosis of mild carpal tunnel syndrome. Muscle Nerve 1993;16:1366-73.

36. Aygül R, Ulvi H, Kotan D, Kuyucu M, Demir R. Sensitivities of conventional and new electrophysiological techniques in carpal tunnel syndrome and their relationship to body mass index. J Brachial Plex Peripher Nerve Inj 2009;4:12.

37. Pease WS, Cannell CD, Johnson EW. Median to radial latency difference test in mild carpal tunnel syndrome. Muscle Nerve 1989;12:905-9.

38. Leblebici B, Adam M, Bagış S, Akman MN. The usefulness of latency difference tests of median-ulnar and medianradial nerves in mild carpal tunnel syndrome. Turk J Phys Med Rehab 2008;54:22-6.

39. Eftekharsadat B, Ahadi T, Raissi GR, Shakoory SK, Fereshtehnejad SM. Validity of current electrodiagnostic techniques in the diagnosis of carpal tunnel syndrome. Med J Islam Repub Iran 2014;28:45. 